АВТОМАТИЗОВАНІ СИСТЕМИ ЕЛЕКТРИЧНОГО ТРАНСПОРТУ

УДК 621.331.1

\title{
АНАЛІЗ ДИНАМІЧНИХ ХАРАКТЕРИСТИК КОМБІНОВАНОГО ФІЛЬТРА ТЯГОВОї ПІДСТАНЦІї
}

Д-р техн. наук Я.В. Щербак, асп. Ю.О. Семененко

\section{АНАЛИЗ ДИНАМИЧЕСКИХ ХАРАКТЕРИСТИК КОМБИНИРОВАННОГО ФИЛЬТРА ТЯГОВОЙ ПОДСТАНЦИИ}

Д-р техн. наук Я.В. Щербак, асп. Ю.А. Семененко

\section{ANALYSIS OF DYNAMIC CHARACTERISTICS COMBINING A FILTER TRACTION SUBSTATIONS}

Doct. of techn. sciences J.V. Shcherbak, postgraduate J.A. Semenenko

У статті проведений аналіз динамічних прочесів активного фільтра послідовного типу, щьо застосовується для покращення якості електричної енергї на виході тягової підстаниії постійного струму.

Ключові слова: комбінований фільтр, динамічні характеристики, електрична енергія, випрямлена напруга, передавальна функиія, розімкнута система.

В статье проведен анализ динамических проиессов активного фильтра последовательного типа, который целесообразно применять для улучшения качества электрической энергии на выходе тяговой подстанции постоянного тока.

Ключевые слова: комбинированный фильтр, динамические характеристики, электрическая энергия, выпрямленное напряжение, передаточная функция, разомкнутая система.

In this paper the analysis of dynamic processes active filter serial-type, used to improve the quality of electric power at the output of the DC traction substation. It is advisable to apply for DC traction substations to suppress the variable component of the rectified voltage, which is the source of interfering effects on circle rail robot, automation and communication. In practice, the operation of electric power systems of transport, the use of passive filtration method has some significant drawbacks, which requires finding more effective methods. The use of passive filter to suppress low frequency harmonics noncanonical is impractical due to significant growth of mass and size parameters. Increasing the degree of filtering ripple is achieved by using combined systems, which are connected by a combination of a specific pattern of passive and active filters.

Keywords: filter combination, the dynamic characteristics of the electrical energy, the rectified voltage transfer function, open loop system.

Вступ. Застосування в системах залізничної автоматики мікропроцесорних пристроїв вимагає зниження впливу тягового струму на рейкові кола. Це 
ставить задачу зниження величини змінної складової випрямленої напруги тягової підстанції.

Постановка проблеми у загальному вигляді та іï зв'язок із важливими науковими та практичними завданнями. Змінна складова випрямленої напруги тягової підстанції постійного струму $\epsilon$ джерелом заважаючого впливу на кола залізничної автоматики та зв'язку. Як показує практика експлуатації систем електропостачання електричного транспорту, застосування пасивних методів фільтрації має ряд суттєвих недоліків, що вимагає пошуку більш ефективних методів.

Аналіз останніх досліджень i публікацій. Аналізу пасивних методів фільтрації присвячений цілий ряд робіт, в яких показана оптимальність застосування в потужних системах живлення LCфільтрів як одноланкових, так i багатоланкових [2-4]. Порівняльний аналіз ефективності використання фільтрів показує, що застосування пасивних фільтрів доцільно тільки для придушення канонічних гармонік [1].

Застосування пасивних фільтрів для придушення низьких частотних неканонічних гармонік є недоцільним через значне зростання їх масогабаритних показників.
Підвищення ступеня фільтрації пульсації досягається застосуванням комбінованих систем, які являють собою комбінацію з'єднаних за певною схемою пасивного та активного фільтра [5-7].

Порівняльний аналіз схем активних фільтрів для силових перетворювальних установок викладений у [6].

Визначення мети та задачі дослідження. Метою даної роботи $\epsilon$ аналіз динамічних процесів активного фільтра послідовного типу, що застосовується для покращення якості електричної енергії на виході тягової підстанції постійного струму.

Основна частина дослідження. Схема комбінованого фільтра наведена на рис. 1. Пасивна ланка фільтра складається 3 індуктивності L та конденсатора C. Активна ланка складається 3 підсилювача K, вихідний сигнал якого через трансформатор Т подається в коло пасивної ланки, динамічної ланки $\mathrm{G}(\mathrm{p})$ та датчика змінної складової вихідної напруги ДЗС. Компенсація пульсаційної складової $\mathrm{U}_{\text {п }}(\mathrm{p})$ здійснюється внесенням у ланцюг пасивної ланки напруги $U_{\kappa}(p)$, яка формується каналом зворотного зв'язку.

Для синтезу динамічних властивостей комбінованого фільтра розглянемо еквівалентну схему, яка наведена на рис. 2.

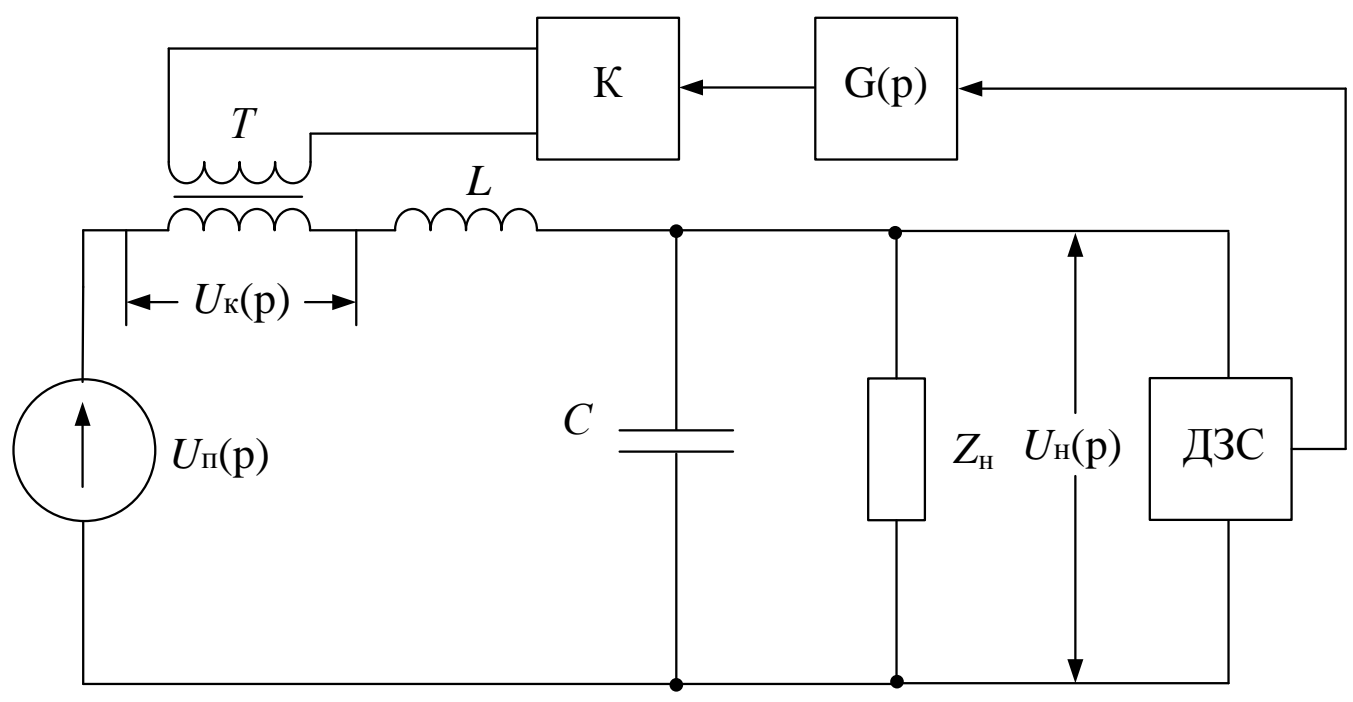

Рис. 1. Структурна схема комбінованого фільтра 


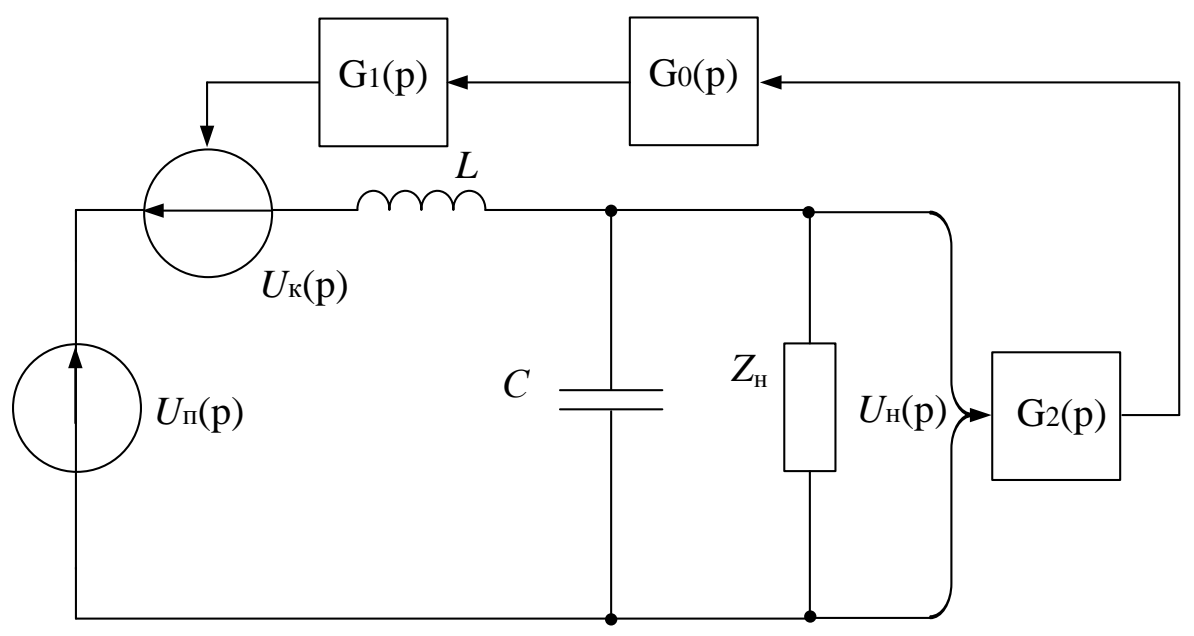

Рис. 2. Еквівалентна схема комбінованого фільтра

Згідно 3 еквівалентною схемою комбінованого фільтра напруга на навантаженні 3 урахуванням активної та пасивної складової фільтра схеми визначається рівнянням

$$
U_{H}(p)=\left[U_{n}(p)-U_{\kappa}(p)\right] \cdot H(p),
$$

де $H(p)=\frac{1}{T_{o}^{2} p^{2}+2 \xi T_{o} p+1}-$ передавальна функція пасивного фільтра;

$T_{0}=\sqrt{L C}-$ постійна часу пасивного фільтра.
Компенсуючий сигнал визначається властивостями кола зворотного зв'язку.

$$
U_{\kappa}(p)=U_{H}(p) \cdot G_{0}(p) \cdot G_{1}(p) \cdot G_{2}(p),
$$

де $G_{l}(p)=K_{1} \frac{T_{1} p}{T_{2} p+1} \quad-\quad$ передавальна функція корегуючої ланки;

$$
G_{2}(p)=\frac{K_{2}}{T_{3} p+1}-\text { передавальна функція }
$$
датчика змінної складової напруги $U_{H}(p)$;

$K_{2}$ - коефіцієнт трансформації.

Підставивши вираз (2) в (1), отримаємо

$$
U_{H}(p)=U_{n}(p) \cdot H(p)-U_{H}(p) \cdot G_{0}(p) \cdot G_{1}(p) \cdot G_{2}(p) \cdot H(p) .
$$

Рівнянню (3) відповідає структурна схема, що наведена на рис. 3.

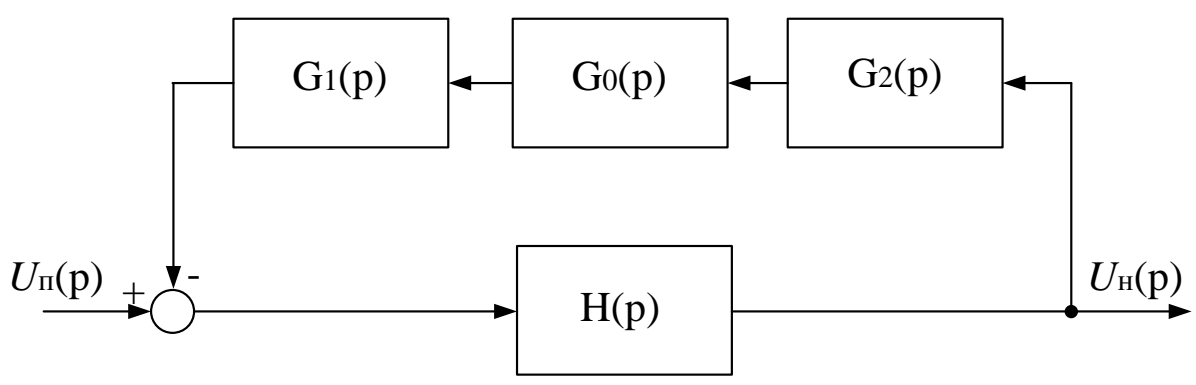

Рис. 3. Структурна схема комбінованого фільтра

Згідно із структурною схемою, фільтра визначається як передавальна функція комбінованого 


$$
W(p)=\frac{U_{H}(p)}{U_{n}(p)}=\frac{H(p)}{1+G_{0}(p) \cdot G_{1}(p) \cdot G_{2}(p) \cdot H(p)} .
$$

Аналіз виразу (4) вказує на те, що динамічні параметри комбінованого фільтра визначаються властивостями ланки 3 передавальною функцією $G_{0}(p)$. Для синтезу передавальної функції $G_{0}(p)$ доцільно використання методу частотних характеристик. При цьому приймаємо допущення, що трансформатор у смузі пропускання комбінованого фільтра $\epsilon$ безінерційною ланкою. В цьому випадку передавальна функція розімкнутої системи визначається як

$$
W_{p}(p)=G_{1} \cdot H(p)
$$

Логарифмічні частотні характеристики наведені на рис. 4.

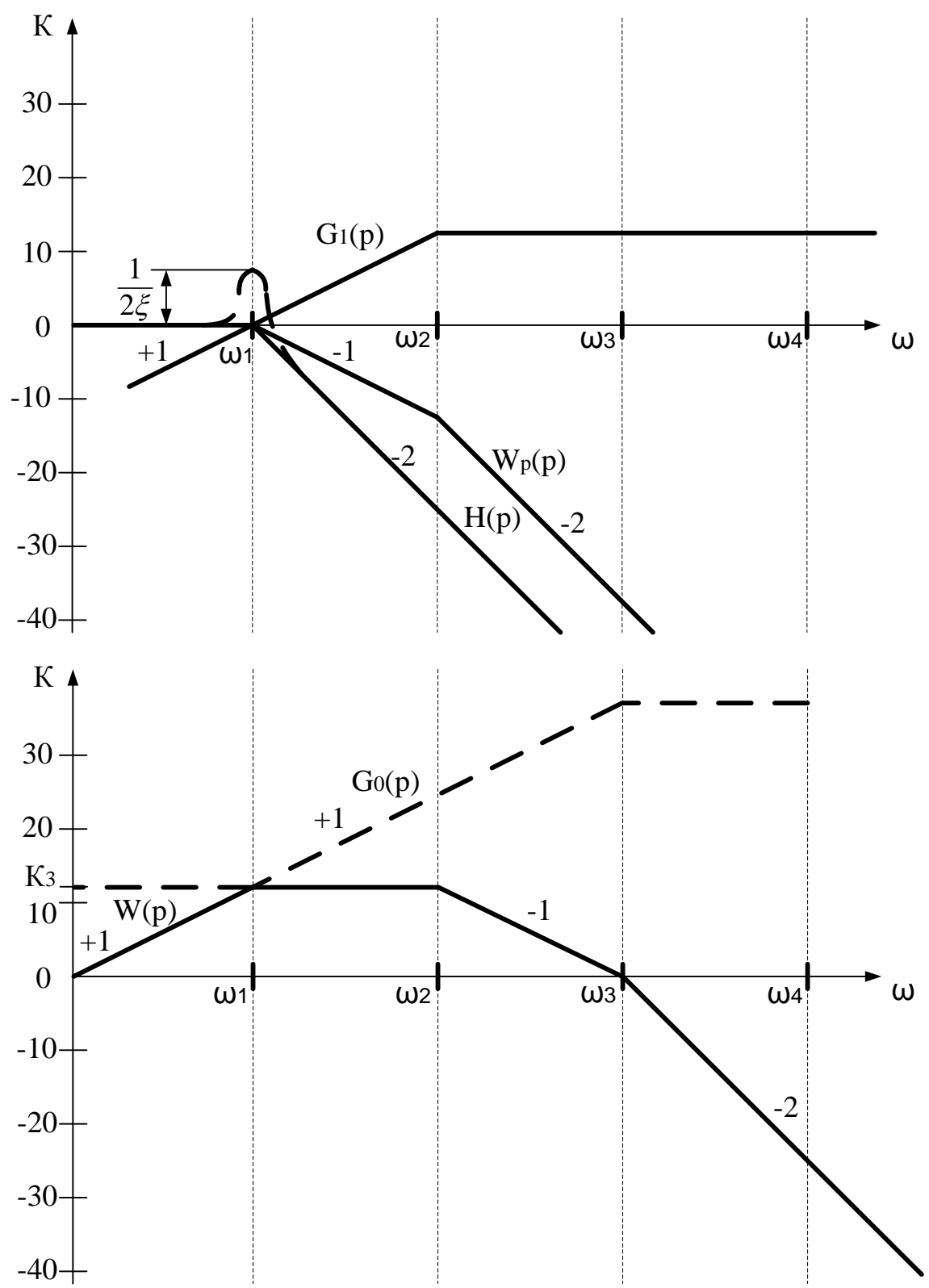

Рис. 4. ЛАХ розімкнутої системи 
Бажана логарифмічна характеристика розімкнутої системи має трапецеїдальну форму. Смуги пропускання, при спаді передачі на 3 дБ, визначаються сполученням частотами $\omega_{1}$ i $\omega_{2}$. За межами смуги пропускання нахил асимптот логарифмічної характеристики складає 20 дБ/дек, що забезпечує достатній запас стійкості і достатньо високу швидкість у перехідних режимах.
Передавальна функція корегуючої ланки має вигляд

$$
G_{0}(p)=K_{3} \frac{T_{1} p+1}{T_{3} p+1}
$$

Для перевірки та підтвердження достовірності результатів теоретичних досліджень була розроблена імітаційна коп'ютерна модель активного фільтра послідовного типу в середовищі MATLAB (рис. 5).

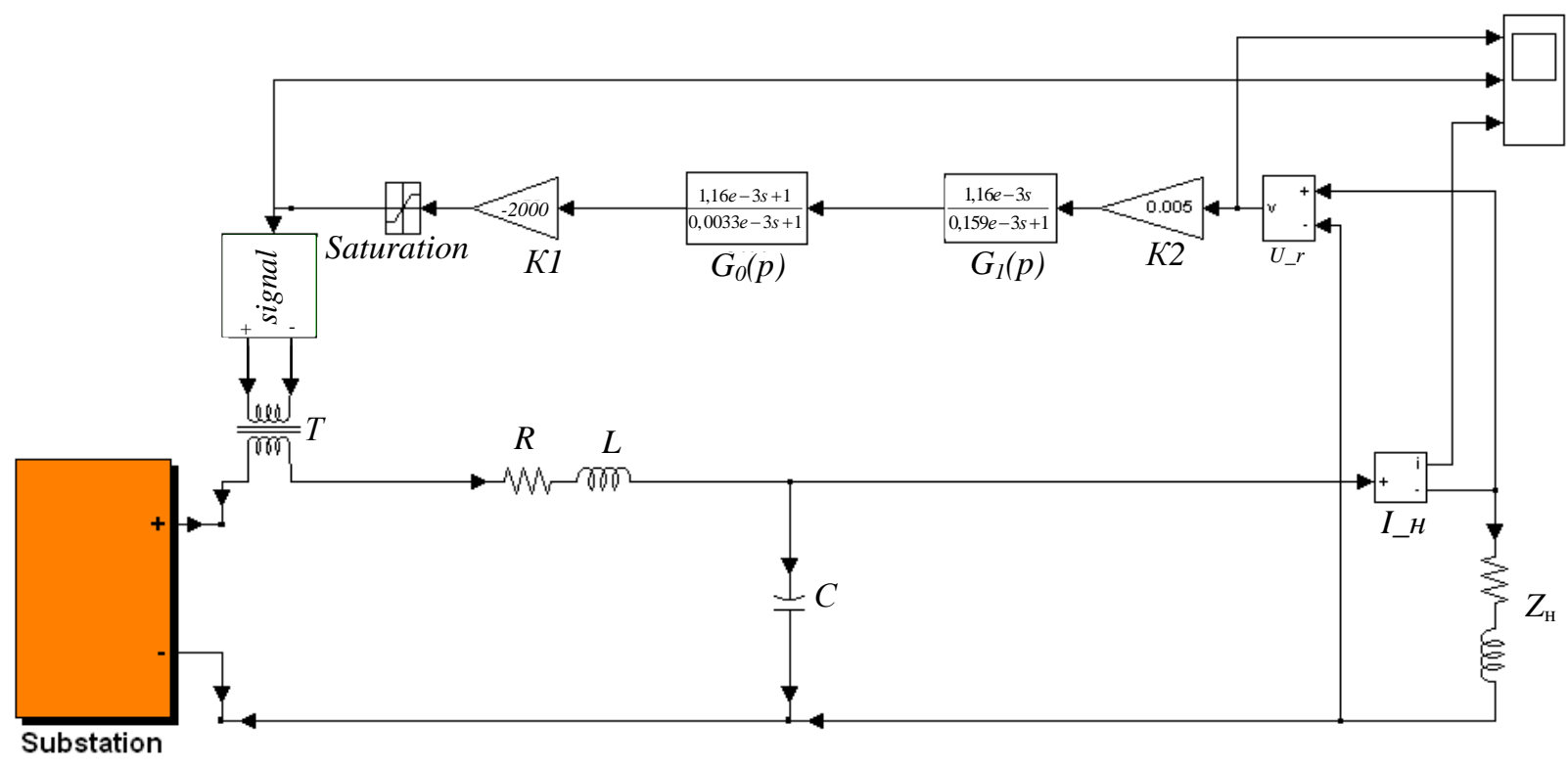

Рис. 5. Імітаційна модель запропонованого активного фільтра послідовного типу в середовищі MATLAB

В даній комп'ютерній моделі блок Substation імітує роботу трифазної мережі живлення. Сигнал струму навантаження $Z_{\mathrm{H}}$ вимірюється блоком I_н, і через послідовно 3'єднані два блоки $\mathrm{G}_{0}(\mathrm{p})$ та $\mathrm{G}_{1}(\mathrm{p}) \quad 3$ передавальними функціями, поданими вище, та підсилювачі К1 і К2, надходить на вхід блока signal, який у свою чергу формує компенсуючий сигнал. Розділяючий трансформатор Т служить для гальванічної розв'язки силової частини схеми та блока signal. Детермінований Г-подібний пасивний фільтр представлений
Згладжувальним реактором L та конденсатором С.

На рис. 6 подані графіки, де перша крива відповідає напрузі на навантаженні без активного фільтра, а друга крива - при роботі активного фільтра. Як видно, пульсаційна складова напруги навантаження значно компенсована.

Аналіз поданих на рис. 6 графіків вказує, що даний активний фільтр послідовного типу забезпечує достатньо високу ефективність компенсації гармонік у широкому діапазоні частот. 

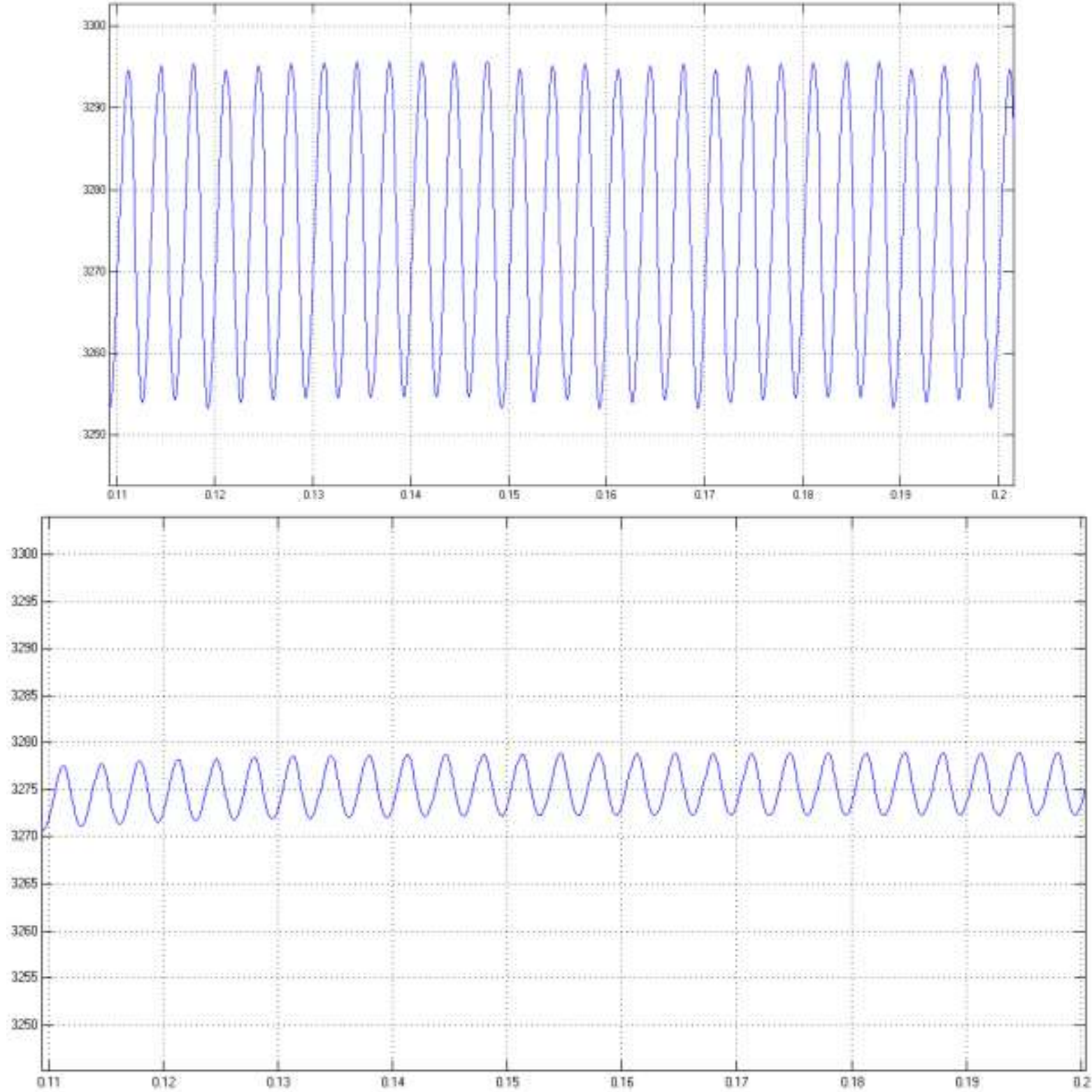

Рис. 6. Графіки напруги навантаження без активного фільтра (зверху) та з ним (знизу)

Висновки 3 дослідження i перспективи, подальший розвиток даному напрямку. Детальний аналіз динамічних процесів активного фільтра послідовного типу показав, що його застосування доцільно для покращення якості електричної енергії на виході тягової підстанції постійного струму, що досягається за рахунок компенсації гармонік напруги та струму контактної мережі в широкому діапазоні частот. Таким чином досягається необхідний рівень електромагнітної сумісності із суміжними електроустановками, а також зменшується вплив тягового струму на рейкові кола в системах тягового електропостачання постійного струму без значного ускладнення та подорожчання систем фільтрації тягової підстанції. 


\section{Список використаних джерел}

1. Щербак, Я.В. Анализ электромагнитных процессов в фильтрующей установке тяговой подстанции постоянного тока [Текст] / Я.В. Щербак, И.В. Слободчиков // Інформаційно-керуючі системи на залізничному транспорті. - 2007. - №4 - С. 48-52.

2. Рябенький, В.М. Сравнительный анализ сглаживающих фильтров на основе обобщенной Т-образной схемы [Текст] / В.М. Рябенький // Изв. вузов СССР. Сер. Энергетика. - 1977. - №7. - С. 140-144.

3. Рябенький, В.М. О выборе схемы пассивного фильтра для сглаживания выпрямленного напряжения [Текст] / В.М. Рябенький, Я.Ф. Анисимов // Труды Николаевского кораблестроительного института. - Николаев: НКИ, 1973. - Вып. 73. - С. 4753.

4. Гольдштейн, Е.И. Проектирование сглаживающих фильтров [Текст] / Е.И. Гольдштейн, А.К. Маер. - Томск: Изд-во ТГУ, 1971. - 171 с.

5. Губаревич, В.Н. Основы проектирования активных энергетических фильтров [Текст] / В.Н. Губаревич, В.М. Рябенький, А.А. Шерман // АН УССР. - К.: ИЭД, 1979. - №192. $44 \mathrm{c}$.

6. Гусев, И.И. Активные энергетические фильтры для мощных преобразователей [Текст] / И.И. Гусев, А.А. Шерман // Современные задачи преобразовательной техники. - К.: ИЭД АН УССР, 1975. - Т.6. - С. 284-295.

7. Гусев, И.И. Активный фильтр компенсационного типа для мощных вентильных преобразователей [Текст] / И.И. Гусев, А.А. Шерман, Г.В. Ахвердян [и др.] // ЭП. Преобразовательная техника. - 1980. - №4. - С. 15-18.

8. Щербак, Я.В. Активна фільтрація вихідної напруги тягової підстанції постійного струму [Текст] / Я.В. Щербак., Ю.О. Семененко // Зб. наук. праць Укр. держ. акад. залізнич. трансп. - Харків: УкрДАЗТ, 2011. - №127. - С. 146-151.

Щербак Яків Васильович, д-р техн. наук, професор, завідувач кафедри автоматизованих систем електричного транспорту Української державної академії залізничного транспорту. Тел.: (057) 730-10-73.

E-mail:sherbak47@mail.ru

Семененко Юрій Олександрович, аспірант кафедри автоматизованих систем електричного транспорту

Української державної академії залізничного транспорту.

Тел.: (057) 730-10-74. E-mail: slider2012@i.ua

Shcherbak Jakiv Vasylovyvch, Doctor of Technical Sciences Professor Head of Department Department automated electric vehicle Ukrainian State Academy of Railway Transport tel.: (057) 730-10-73. E-mail: sherbak47@mail.ru Semenenko Juriy Aleksandrovivch, Postgraduate Department automated electric vehicle Ukrainian State Academy of Railway Transport tel.: (057) 730-10-74.E-mail: slider2012@i.ua 